\title{
Hereditary risk factors for the development of gastric cancer in
} younger patients

\author{
Mohammad Yaghoobi*, Naser Rakhshani, Farhad Sadr, Raheleh Bijarchi, \\ Yasamin Joshaghani, Ashraf Mohammadkhani, Arezou Attari, \\ Mohammad Reza Akbari, Mahshid Hormazdi and Reza Malekzadeh
}

Address: Digestive Disease Research Center, Tehran University of Medical Sciences, Shariati Hospital, Kargar Shomali St, Tehran 14114, Iran

Email: Mohammad Yaghoobi* - yaghoobi@ams.ac.ir; Naser Rakhshani - rakhshani@ddrcir.org; Farhad Sadr - sadr_ddrcir@yahoo.com; Raheleh Bijarchi - rahelehbi@yahoo.com; Yasamin Joshaghani - joshaghani_ddrcir@yahoo.com;

Ashraf Mohammadkhani - mohammadkhani@ddrcir.org; Arezou Attari - attari1382@yahoo.com; Mohammad Reza Akbari - akbari@ddrcir.org; Mahshid Hormazdi - hormozdi_ddrc@yahoo.com; Reza Malekzadeh - malek@ams.ac.ir

* Corresponding author

Published: 27 October 2004

BMC Gastroenterology 2004, 4:28 doi:10.1 186/147/-230X-4-28

This article is available from: http://www.biomedcentral.com/I47I-230X/4/28

(c) 2004 Yaghoobi et al; licensee BioMed Central Ltd.

This is an open-access article distributed under the terms of the Creative Commons Attribution License (http://creativecommons.org/licenses/by/2.0), which permits unrestricted use, distribution, and reproduction in any medium, provided the original work is properly cited.
Received: 29 January 2004

Accepted: 27 October 2004

\begin{abstract}
Background: It is believed that the development of gastric cancer (GC) before the age of 50 has a hereditary basis. Blood group $A$ and history of gastric cancer in first-degree relatives have been shown to be risk factors for GC.

Methods: In this case-control study, we enrolled patients with GC who were diagnosed before the age of 50. Patients who were diagnosed as having GC were selected. A total of 534 cases were found; of these, 44 diagnosed before the age of 50 were included in the case group. For the control group, 22 males and 22 females were randomly selected from the remaining subjects, who had diagnoses of GC after the age of 50 . All the surviving patients and family members of the dead patients were interviewed about the history of cancer in the family and the age at which other family members developed cancer. The blood group of each subject was also obtained.
\end{abstract}

Results: forty-four cases under 50 years old (mean age: 36.2 years) and forty-four controls (mean age: 67.1 years) were enrolled in the study. At the time of the study, $59.1 \%$ of the study group and $50 \%$ of the control group were alive (P value $=N S$ ). In the study group, $68.1 \%, 13.6 \%, 13.6 \%$ and $4.5 \%$ had blood groups $\mathrm{O}, \mathrm{A}, \mathrm{B}$ and $\mathrm{AB}$, respectively. In the control group the corresponding figures were $27.7 \%, 63.6 \%, 6.8 \%$ and $4.5 \%$. First or second-degree relatives with cancer, including gastric (the most frequent), breast, lung, gynecological and hematological malignancies, were noted in $54.5 \%$ of the cases and II.4\% of the controls $(p<0.01)$. Family histories of cancer were accepted as valid provided that they were based on valid medical documents.

Conclusions: It seems that the development of GC before the age of 50 is likely to be accompanied by familial susceptibility. Interestingly, our study showed a significant correlation between blood group $\mathrm{O}$ and the development of gastric cancer under the age of 50 . 


\section{Background}

Gastric cancer is the second most common cause of cancer-related death in the world [1]. Its incidence varies considerably worldwide [2]. In general, it is a larger problem in developing countries than in industrialized nations, and shows a predilection for urban and lower socioeconomic groups [3,4]. The estimated crude rate accounts for approximately $9.9 \%$ of cancers worldwide [5]. Gastric cancer rarely occurs before the age of 40 . The incidence rises steadily thereafter, peaking in the seventh decade. Men are nearly twice as susceptible as women. This cancer alone is the cause of more than 750,000 deaths per annum in the world [6]. Marked variation within countries has also been observed [3,4], particularly in high-risk countries [7]. In developing countries, the overall incidence of gastric cancer is increasing and projections indicate that the annual number of new cases will increase significantly during the next few decades as a result of adult population growth [6]. A recent cancer survey by the Iranian Ministry of Health and Medical Education revealed that gastric adenocarcinoma is the most common fatal cancer in Iran, with a wide variation of death rate among different provinces [8]. According to recent cancer statistics, deaths due to gastric cancer constitute about $39 \%$ of all deaths due to cancer each year in some parts of Iran [9].

The reduced incidence of gastric cancer in western countries reflects a decrease in cancers arising in the distal stomach (body and antrum). In contrast, the incidence of cancer in the proximal stomach and esophagogastric junction has steadily increased, at a rate exceeding that of any other cancer except melanoma and lung cancer [10-13]. In a very recent study, our group showed that cardiac cancer constitutes $49.5 \%$ of all sites for gastric cancer in Iran. In contrast, cancers of body and antrum comprise $20.6 \%$ and $29.9 \%$ respectively [9]. Unlike cancer of the distal stomach, cancers of the proximal stomach and esophagogastric junction are more common among higher socioeconomic classes [6]. Overall, these observations suggest that proximal cancers share a similar pathogenesis, which is distinct from that of distal cancers. Zanghieri and La Vecchia found that about $10 \%$ of cases show familial clustering. Epidemiological studies have shown that the risk of gastric cancer in first-degree relatives is increased 2- to 3-fold [14-17]. The relative contributions of inherited susceptibility and environmental effects on familial gastric cancer are poorly understood.

In general, familial genetic mechanisms do not play as important a role in gastric cancer as they do in e.g. colorectal cancer. Nonetheless, in some regions, a family history of gastric cancer may be a risk factor for the disease, although this might reflect environmental factors shared by members of a family [18]. Rate collections of familial aggregates of gastric cancer have been reported, but are distinctly unusual. As yet there is no comprehensive hypothesis for the development of gastric cancer. Gastric cancers are associated with chromosomal aberrations and other genetic defects, but none of these is necessary or sufficient for cancer to occur.

In a review about genetic predisposition to gastric cancer, Bevan and Houlston (1999) concluded that several genes may be associated with increased risk [19]. Gastric cancer is a manifestation of several inherited cancer predisposition syndromes including hereditary nonpolyposis colon cancer, familial adenomatous polyposis, Peutz-Jeghers syndrome and Cowden disease. This suggests the presence of predisposing genes with different effects.

Many studies have addressed the correlation between $\mathrm{ABO}$ antigens and the development of gastric cancer, but most of these have indicated a correlation between sporadic cases of gastric cancer and blood group A. This association further supports the role of genetic factors in the development of gastric cancer [21]. Blood type A is more strongly associated with the diffuse histopathological type of gastric cancer than the intestinal type [21,22]. To our knowledge, similar studies on the specific category of gastric cancer in younger patients are scanty. This may be one of the first studies on the role of hereditary factors in the development of the gastric cancer in younger patients.

\section{Methods}

The study was designed as a case-control study. We set up an active surveillance to identify patients with gastric cancer. Patients' records in the department of pathology in the main private referral facility in Tehran were scrutinized for gastric cancer cases between 1999 and 2003. Patients are referred here from all regions of the country and from different ethnic backgrounds and they are operated upon in the same hospital, so all the operation and pathology reports were available simultaneously. All the pathology reports were prepared and diagnosed by the same pathologists. The cases were selected from patients who were diagnosed with gastric cancer before the age of fifty. The sex-matched controls were randomly selected and enrolled from patients who were diagnosed over the age of fifty. All the patients and their family were interviewed regarding the history of gastric or other types of cancer over three generations, and the blood groups of affected members were ascertained. Family histories of cancer were accepted as valid provided that they were based on valid medical documents. The transfusion records of the operation were also used to identify the patients' blood groups.

Statistical analysis was performed using the SPSS Statistical Package (version 10.0). The quantitative variables were 
Table I: The pathologic characteristics of the tumor in the case and control group ( $\mathrm{n}=\mathbf{4 4}$ in each group).

\begin{tabular}{|c|c|c|c|c|c|c|}
\hline \multirow[b]{2}{*}{ Case group } & \multicolumn{2}{|c|}{ Pathologic differentiation } & \multicolumn{2}{|c|}{ Pathologic Type } & \multicolumn{2}{|c|}{ Location of the tumor } \\
\hline & Well differentiated & $1.4 \%$ & Diffuse & $0.5 \%$ & Cardia & $13.6 \%$ \\
\hline & Moderately differentiated & $5.0 \%$ & & & Body & $18.2 \%$ \\
\hline & Poorly differentiated & $1.4 \%$ & Intestinal & $7.3 \%$ & Distal & $68.2 \%$ \\
\hline \multirow[t]{3}{*}{ Control group } & Well differentiated & $7.3 \%$ & Diffuse & $5 \%$ & Cardia & $22.7 \%$ \\
\hline & Moderately differentiated & $5.0 \%$ & & & Body & $29.5 \%$ \\
\hline & Poorly differentiated & $7.7 \%$ & Intestinal & $5 \%$ & Distal & $47.7 \%$ \\
\hline$P$ value & & NS & & NS & & NS \\
\hline
\end{tabular}

expressed as means (minimum-maximum) when appropriate. A chi-square test was performed to ascertain the overall effect of blood group on the development of gastric cancer before the age of 50. All statistical tests were two-sided and differences at the 0.01 level were considered statistically significant.

\section{Results}

At the beginning of the study, 44 cases (mean age: 36.2, $18-49 ; \mathrm{m} / \mathrm{f}=1)$ under 50 years old and 44 sex-matched controls (mean age: 67.1, 50-88) were enrolled. Table 1 shows the pathological characteristics of all 88 subjects. At the time of the study, $59.1 \%$ of the case group and $50 \%$ of the control group were alive; $53.8 \%$ of the case group and $38.6 \%$ were living in Tehran, but no information on residence background was available. Data regarding firstdegree relatives were complete for both groups. These data comprised information on 383 persons in the case group (average 9.1 for each proband) and 498 in the control group (average 11.6 for each proband). Table shows the distribution of blood groups in the two subject groups. Gastric (22 cases) and other types of cancer were reported in $54.5 \%$ of the first-degree relatives of the cases and $11.4 \%$ of the first-degree relatives of the controls ( $p<$ $0.01)$. The "other types of cancer" among relatives of the case group comprised colorectal ( 7 cases), breast ( 3 cases), lung ( 3 cases), gynecological ( 2 cases), hematological ( 1 case) and bladder ( 1 case) malignancies. For the control group, the corresponding figures were colorectal (2 cases), breast ( 1 case), lung ( 1 case) and prostate ( 1 case) malignancies. Figures 1, 2, 3 show three pedigrees of familial connections.

Table 2: Frequency of the different blood groups in the study population $(n=44)$. The figures in parentheses are the number of the patients.

\begin{tabular}{lllll}
\hline Blood group & $\mathrm{O}$ & $\mathrm{A}$ & $\mathrm{B}$ & $\mathrm{AB}$ \\
\hline Cases & $(30) 68.1 \%$ & $(6) 13.6 \%$ & $(6) 13.6 \%$ & $(2) 4.5 \%$ \\
Controls & $(11) 27.3 \%$ & $(28) 63.6 \%$ & $(3) 6.8 \%$ & $(2) 4.5 \%$ \\
P value & $<0.05$ & $<0.01$ & NS & NS \\
\hline
\end{tabular}

\section{Discussion}

This case control study demonstrates that hereditary factors, especially familial history of cancer and possession of blood group $\mathrm{O}$, are associated with the development of gastric cancer under the age of fifty. To our knowledge, this may be the first study showing a correlation between blood group $\mathrm{O}$ and the development of gastric cancer in a specific category of patients.

Risk factors for gastric cancers have been explored in a number of previous studies, including genetic factors such as blood group. Haenszel et al. suggested an association between gastric cancer and blood type A, supporting the view that genetic factors have a role in the development of gastric cancer [21]. Our study emphasizes the role of genetic factors in one subcategory of patients, those who develop gastric cancer under the age of fifty. Blood group A is more strongly associated with the diffuse histopathological type of gastric cancer than the intestinal type $[21,22]$. In our study, most of the patients had a diffuse rather than intestinal type, so we could not test this association. A larger sample size would be needed. On the other hand, there might be a higher prevalence of Helicobacter pylori in our community, causing a higher incidence of the diffuse type of gastric cancer. However, there were no significant differences in histological type of gastric cancer between the case and control groups. In a study by Su et al. in 2001, a total of 6685 patients with esophageal carcinoma and 2955 patients with cardiac cancer in the Chaoshan district were retrospectively assessed for their association with $\mathrm{ABO}$ blood groups. Su et al. showed that the distribution of $\mathrm{ABO}$ blood groups in patients with esophageal carcinoma or cardiac cancer was similar to that in the normal local population, but there was an association between blood group $\mathrm{B}$ and the development of cancer of cardia in males [23].

In our study, approximately $54 \%$ of the case group had a familial history of cancer compared to $11 \%$ of the control group. This seems compatible with the findings of a population-based case-control study of stomach cancer in Warsaw, Poland. Here, the investigators interviewed 464 


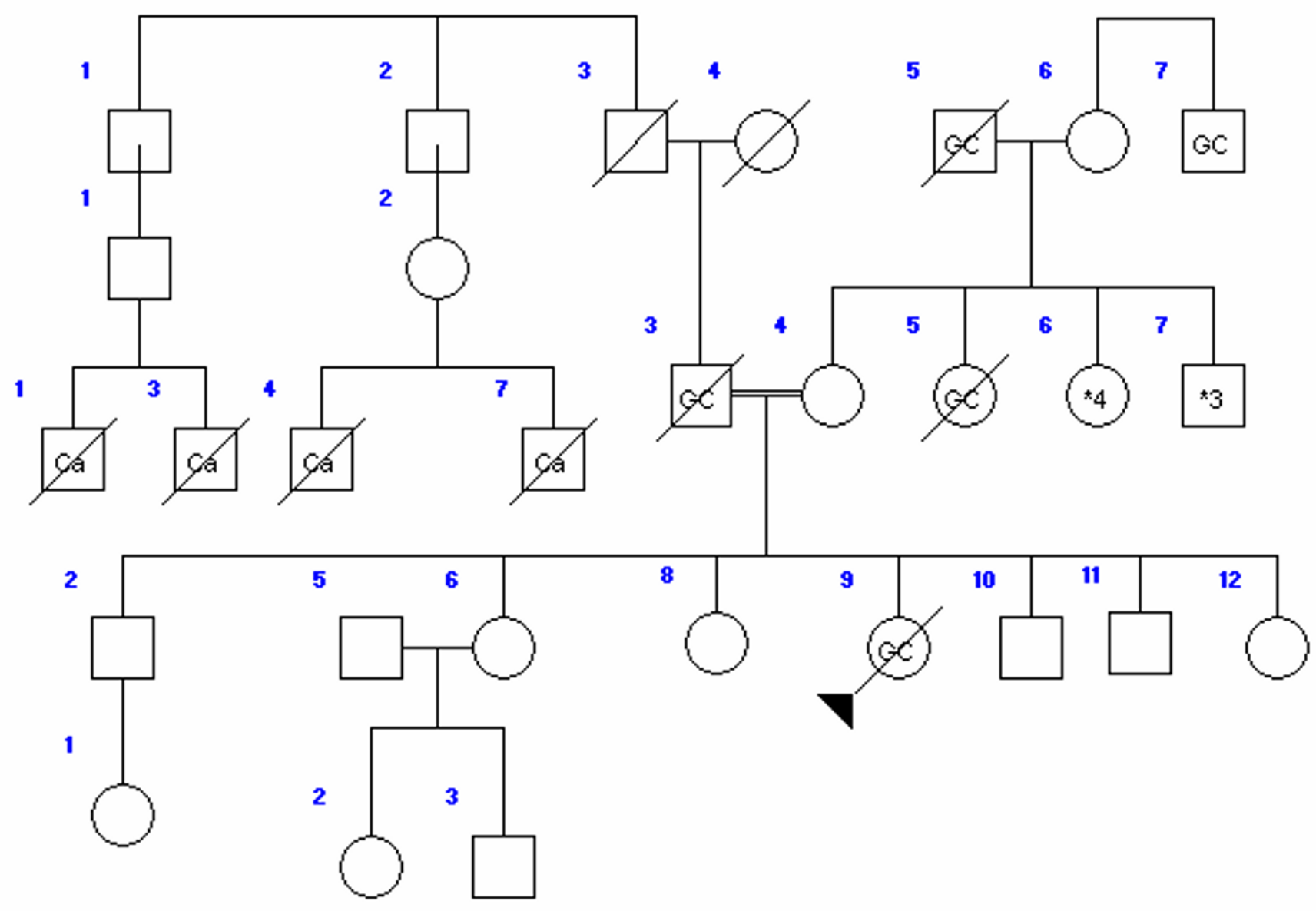

Figure I

A family with aggregation with gastric cancer (GC: Gastric Cancer; Ca: History of gastric cancer but not confirmed by a pathologic reports for the histologic type of cancer).

cases and 480 controls to evaluate the role of family history and other risk factors. A greater than threefold increase in risk was associated with a history of gastric cancer in a first degree relative $(\mathrm{OR}=3.5)$, but no excess risk was seen for other forms of cancer. The risk associated with familial occurrence was not significantly modified by gender, age or $\mathrm{ABO}$ blood type, and did not vary with Lauren histological classification24. Despite the relatively large sample size in the Polish study, younger patients were not evaluated as a separate category. This may explain the difference between their results and ours. Furthermore, they defined "positive family history" as having a first-degree relative with gastric cancer. In contrast, we considered all types of malignancy in first and seconddegree relatives; though the familial incidence of other (non-GI) malignancies in our study may reflect their higher frequency in the community rather than any genetic risk factor. The Polish study did not confirm previous results on the correlation between blood group A and gastric cancer. Moreover, another study by Parsonnet et al on 90 cases and 89 controls showed no association between $\mathrm{ABO}$ blood group and malignancy [25]. In a multicentric study in Italy, 1016 patients with gastric cancer and 1623 population controls were interviewed to determine family histories of gastric, esophageal and colorectal cancer. A significant association was found with history of gastric cancer in a sibling or parent (odds ratios 2.6 and 1.7, respectively). Among the adult siblings of controls and cases, the prevalences of gastric cancer reported at interview were 1 and $2.7 \%$, respectively. A further increase was noted in families with at least one affected parent (1.4 and 5.7\%). The risk of gastric cancer 


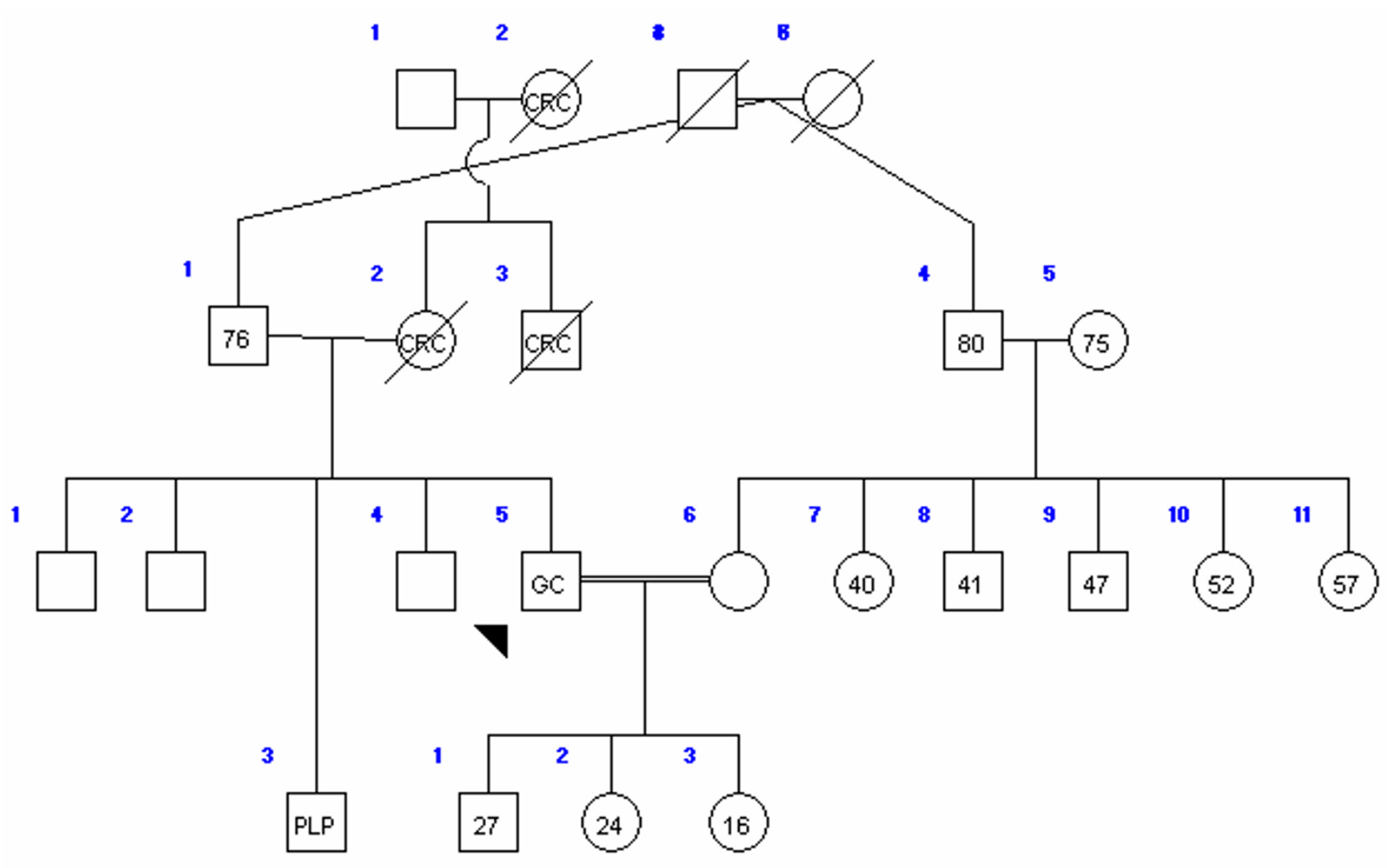

Figure 2

A family with a history of the aggregation with Colorectal cancer (GC: Gastric Cancer; CRC: Colorectal Cancer; PLP: Colorectal Polyps; Numbers in circles: Current age of the persons; CAG: Chronic Active Gastritis).

associated with a positive family history was greater (increased about 2-fold) among residents of low-risk areas. Among the cases, there was no relationship between family history of gastric cancer and blood group A or histological type according to the Lauren classification [26]. In our study, there was no significant relationship between the histological type of the cancer and positive family history or blood group. However, this does not prove that the two variables do not correlate; an association might become apparent with a larger study. Mecklin et al studied the clinical and histopathological characteristics of gastric carcinoma in young patients (under 40 years old) in Finland in 1988. In 94\% of the young patients, the carcinoma was of the diffuse type. They showed a poor prognosis, an equal sex ratio, and a strong association with blood group A in their study group. They also found a highly significant over-representation of gastric cancer in the parents of the index cases $(\mathrm{p}<0.001)$ [27]. The difference between Mecklin's study and ours in the blood groups identified as risk factors may reflect ethnic differences; both studies confirm a significant correla- tion between a specific blood group and the development of gastric cancer. Future studies may use linkage analysis to detect genetic abnormalities in chromosomal regions that are located near the genes encoding the $\mathrm{ABO}$ antigens.

Matching the geographical origins of the cases and controls could have improved the power of our study by excluding ethnic factors from the study population. However, this is very difficult to achieve in such studies because there is a high rate of combinations between races in the country. In addition, the sample size was too small for such effects to be excluded. However, there were no significance differences between the two groups in respect of the origins of the subjects.

In conclusion, our results show that familial history of cancer, and hereditary factors including blood group, have a role in the development of gastric cancer in young patients. The role of environmental factors may be more 


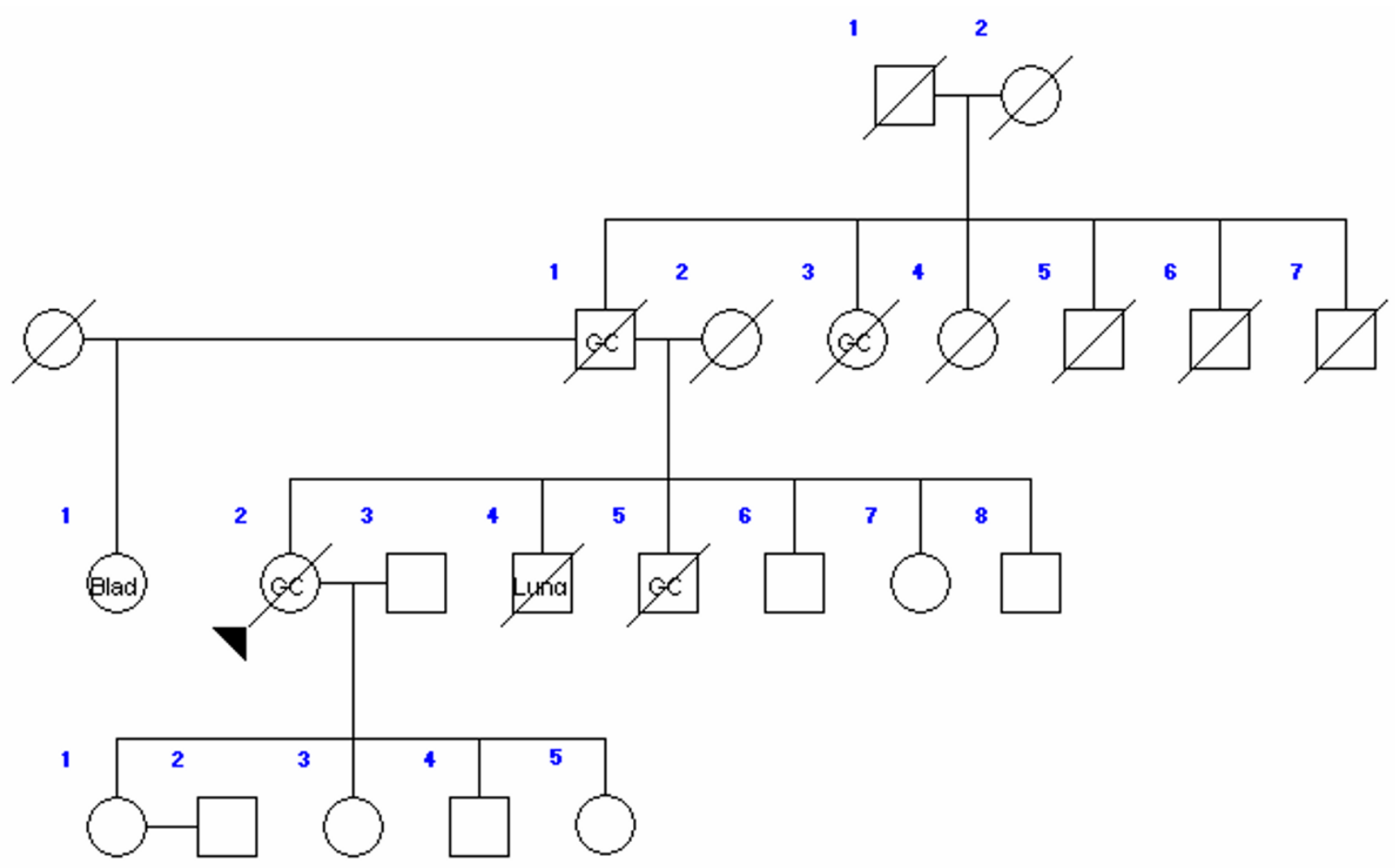

Figure 3

A family with a history of the aggregation with other cancers as well as gastric cancer (GC: Gastric Cancer; Lung: Lung Cancer; Blad: Bladder Carcinoma).

important in older patients and can be considered in future studies.

\section{Competing interests}

The authors declare that they have no competing interest.

\section{Authors' contributions}

MY designed and assisted in the conduction of the study, analyzing of the data and draft the manuscript.

$\mathrm{NR}, \mathrm{FS}, \mathrm{RB}$ and $\mathrm{YJ}$ assisted in the conducting and designing the study and interview with the study cases as well as drafting manuscript.

$\mathrm{AM}$ and MA assisted in analyzing of the study and conducting interviews.

AA and $\mathrm{MH}$ reviewed and approved the pathology reports of the patients and case collecting.
RM supervised the study scientifically and executively and assisted in drafting the manuscript.

All authors read and approved the final manuscript.

\section{Acknowledgements}

The authors wish to thanks Christian Abnet PhD and Sanford Daisy MD, Cancer Prevention Branch, National Cancer Institute, Bethesda, MD, USA for their help in providing the software for pedigree drawing as well as David G. Huntsman, MD, FRCPC, FCCMG, and Pardeep Kaurah, University of British Columbia, Vancouver, Canada for kind help regarding the questionnaire of familial background.

This study has been granted by the Iranian Network of Molecular Medicine and the Digestive Disease Research Center of Tehran University of Medical Sciences.

\section{References}

I. Coleman MP, Esteve J, Damiecki P, Arslan A, Renard H: Trends in cancer incidence and mortality. IARC Sci Publ 1993, I 2 I: I-806.

2. Whelan SL: Cancer incidence in five continents. IARC Sci Publ 1992, 120:31-8.

3. Hill MJ: Mechanisms of gastric carcinogenesis. Eur J Cancer Prev 1994, 3(Suppl 2):25-9. 
4. Howson CP, Hiyama T, Wynder EL: The decline in gastric cancer: Epidemiology of an unplanned triumph. Epidemiol Rev 1986, 8: I-27.

5. Parkin DM, Pisani, Ferlay J: Estimates of the worldwide incidence of eighteen major cancers in 1993. Int J Cancer 1993, 54(4):594-606.

6. Murray CJ, Lopez AD: Mortality by cause for eight regions of the world: global burden of disease study. Lancet 1997, 349(906 I): 1269-76.

7. Death in four provinces of Iran. Publication of the Ministry of Health and Medical Education 2000.

8. Haghighi P, Nasr K: Gastrointestinal cancer in Iran. J Chronic Dis 1971, 24:625-33.

9. Yazdannbod A, Arshi S, Derakhshan MH, Sadjadi AR, Malekzadeh R: Gastric cardia cancer; the most common type of upper gastrointestinal cancer in Ardabil, Iran: An endoscopy clinic experience. Arch Irn Med 200I, 4(2):76-79.

10. Blot WJ, Devesa SS, Kneller RW, Fraumeni JF Jr: Rising incidence of adenocarcinoma of the esophagus and gastric cardia. JAMA 1991, 265:1287-9.

II. Powell J, McConkey CC: Increasing incidence of adenocarcinoma of the gastric cardia and adjacent sites. Br J Cancer 1990, 62:440-3.

12. Craanen ME, Dekker W, Blok P, Ferwerda J, Tytgat GN: Time trends in gastric carcinoma: Changing patterns of type and location. Am J Gastroenterol 1992, 87(5):572-9.

13. Golematis B, Tzardis P, Hatzikostas P, Papadimitriou K, Haritopoulos $\mathrm{N}$ : Changing pattern of distribution of carcinoma of the stomach. Br J Surg 1990, 77:63-4.

14. Zanghieri G, Di Gregorio C, Sacchetti C, Fante R, Sassatelli R, Cannizzo G, Carriero A, Ponz de Leon M: Familial occurrence of gastric cancer in the 2-year experience of a population-based registry. Cancer 1990, 66:2047-205I.

15. La Vecchia C, Negri E, Franceschi S, Gentile A: Family history and risk of stomach and colorectal cancer. Cancer 1992, 70:50-5.

16. Brenner H, Arndt V, Sturmer T, Stegmaier C, Ziegler H, Dhom G: Individual and joint contribution of family history and Helicobacter pylori infection to the risk of gastric carcinoma. Cancer 2000, 88:274-9.

17. Inoue M, Tajima K, Yamamura Y, Hamajima N, Hirose K, Kodera Y, Kito T, Tominaga S: Family history and subsite of gastric cancer: Data from a case-referent study in Japan. Int J Cancer 1998, 76:80I-5.

18. Goldgar DE, Easton DF, Cannon-Albright LA, Skolnick MH: Systematic population-based assessment of cancer risk in firstdegree relatives of cancer probands. J Nat Cancer Inst 1994, 86:1600-1608.

19. Bevan S, Houlston RS: Genetic predisposition to gastric cancer. Quart J Med 1999, 92:5-10.

20. Caldas C, Carneiro F, Lynch HT, Yokota J, Wiesner GL, Powell SM, Lewis FR, Huntsman DG, Pharoah PD, Jankowski JA, MacLeod P, Vogelsang H, Keller G, Park KG, Richards FM, Maher ER, Gayther SA, Oliveira C, Grehan N, Wight D, Seruca R, Roviello F, Ponder BA, Jackson $C E$ : Familial gastric cancer: overview and guidelines for management. J Med Genet 1999, 36:873-880.

21. Haenszel W, Kurihara M, Segi M, Lee RK: Stomach Cancer among Japanese in Hawaii. J Natl Cancer Inst 1972, 49:969-88.

22. Fuchs CS, Mayer RJ: Gastric carcinoma [comments]. N Engl J Med 1996, 333(I):32-4I.

23. Su M, Lu SM, Tian DP, Zhao H, Li XY, Li DR, Zheng ZC: Relationship between ABO blood groups and carcinoma of esophagus and cardia in Chaoshan inhabitants of China. World J Gastroenterol 200I, 7(5):657-6I.

24. Lissowska J Groves FD, Sobin LH, Fraumeni JF Jr, Nasierowska-Guttmejer A, Radziszewski J, Regula J, Hsing AW, Zatonski W, Blot WJ, Chow WH: Family history and risk of stomach cancer in Warsaw, Poland. Eur J Cancer Prev 1999, 8(3):223-7.

25. Parsonnet J, Friedman GD, Orentreich N, Vogelman H: Risk for gastric cancer in people with CagA positive or CagA negative Helicobacter pylori infection. Gut 1997, 40(3):297-301.

26. Palli D, Galli M, Caporaso NE, Cipriani F, Decarli A, Saieva C, Fraumeni JF Jr, Buiatti E: Family history and risk of stomach cancer in Italy. Cancer Epidemiol Biomarkers Prev 1994, 3(1):15-8.

27. Mecklin JP, Nordling S, Saario I: Carcinoma of the stomach and its heredity in young patients. Scand J Gastroenterol 1988, 23(3):307-II.

\section{Pre-publication history}

The pre-publication history for this paper can be accessed here:

http://www.biomedcentral.com/1471-230X/4/28/pre

pub
Publish with Biomed Central and every scientist can read your work free of charge

"BioMed Central will be the most significant development for disseminating the results of biomedical research in our lifetime. "

Sir Paul Nurse, Cancer Research UK

Your research papers will be:

- available free of charge to the entire biomedical community

- peer reviewed and published immediately upon acceptance

- cited in PubMed and archived on PubMed Central

- yours - you keep the copyright

Submit your manuscript here:

http://www.biomedcentral.com/info/publishing_adv.asp
BioMedcentral 